\title{
Engineering Education and Technological / Professional Learning
}

\author{
Clara Viegas \\ Polytechnic of Porto - School of \\ Engineering (ISEP) \\ Portugal \\ mcm@isep.ipp.pt
}

\author{
Arcelina Marques \\ Polytechnic of Porto - School of \\ Engineering (ISEP) \\ Portugal \\ mmr@isep.ipp.pt
}

\author{
Gustavo Alves \\ Polytechnic of Porto - School of \\ Engineering (ISEP) \\ Portugal \\ gca@isep.ipp.pt
}

\begin{abstract}
Engineering business is a demanding and dynamic market, which universities must understand and accompany. Being aware of the market needs is a step forward in training successful professionals. The presented works contributed to enhance the present discussion addressing different topics like emergent technologies, professional, scientific and social competences or projects that allow students to perform the first contacts with the real world. The view of students, teachers and company supervisors are considered.
\end{abstract}

\section{CCS CONCEPTS}

- Applied computing $\rightarrow$ Physical sciences and engineering $\rightarrow$ education

\section{KEYWORDS}

Teaching Contexts; Teaching methodologies; Competence Development; Engineering Education; Young Engineers Challenges, PBL.

\section{INTRODUCTION}

Over the last 20 years, few changes were integrated in the way universities teach, comparing with the enormous change felt in the way the market looks for trained young professionals [1]. They look for engineers in two dimensions: technical knowledge and enabling skills. $21^{\text {st }}$ century engineers have to possess a strong technical knowledge, be prepared to exceed themselves to embrace different applications and be willing and comfortable to communicate and motivate their peers. The constant need to work or lead teams which collaboratively mobilize knowledge, integrate several thematic in order to solve problems, analyze data and criticize results in order to come up with solutions, is in everyday agenda [2].

Engineering business is nowadays a demanding and dynamic market, therefore universities must maintain a close communication channel with enterprises. Being aware of the market needs is a step forward in training successful professionals [3].
Engineering Education has been a proficient area in the last decades, alerting teachers, discussing better course of actions with the professionals and pointing for the need to continually change and adapt, which much contributed to some advances observed in engineering schools [4-6].

\section{TECHNOLOGICAL AND PROFESSIONAL LEARNING}

This track purpose is to help identify good practices and some particular issues that young engineers or their employees felt lacking or other topics which still need to be improved. In order to discuss this, different perspectives are needed and welcome, namely from the viewpoint of young engineers and/or senior students, educators, tutors and senior engineers. On the other hand, it would also be most helpful to the freshmen students better understand what exactly is expected from them in the real world: what better than CEOs or former student advices to help them develop the needed intrinsic motivation to learn solving problems and become a true engineer? So, hoping for different perspectives the major topics served as a challenge to involve this community into these discussions were:

- Project work in engineering education

- $\quad$ PBL engineering experiences

- First contacts with engineering profession

- Improving engineering professional, social and/or scientific competences

- Engineering graduate students' competences versus companies' professional needs

- Long term vision about engineering education

- Capstone projects versus professional internships

- Cornerstone projects versus field trips

- Emerging technologies in teaching

- Successful merged practices from Academia and Industries

- Multicultural aspects of engineering education

\section{CONTRIBUTIONS}


This year contributions to this special session at TEEM'18 involved different perspectives on this subject. Some related emergent technologies, others with to teaching issues and a few exploring scenarios closer to professional environments.

\subsection{Emergent Technologies}

Different perspectives related to emergent technologies and their use in engineering education were presented.

"Gamification for formative assessment in the framework of engineering learning" raises an increasingly current issue of the effects of student response systems in the classroom. This work explores how some of the different open source available may modify the student learning process. It is a useful work to the ones that already use this kind of tools to cut out monotony or to the ones who never used it. By better understanding its outcomes teachers can make improved decisions upon its usage and more aware of some cautions.

"Newton's cradle: a smartphone-based video analysis approach" explores a different and inexpensive approach of studying a basic physics concept: elastic collision. Applying the model of momentum and kinetic energy conservation, this work discusses the possibility of students use their smartphones in order to study it. By recording a Newton's cradle movement with the smartphone camera, it is possible to analyze experimental data and draw conclusions. These interactive experiments students feel they could do on their own may prove stimulating to drive their attention.

"Educational content using Blind/Deaf Communications API" brings us a new technological development created to aid fulfill a gap on the deaf and blind communities to access Massive and Open Online Courses. This proposal is based on the development of a post-graduation using automatic translation (through BDC-API architecture) to these communities of the digital educational content. On the other hand, it also allows the blind and deaf to interact and without the need or programming skills they are able to communicate.

\subsection{Improving engineering professional social and/or scientific skills}

The fact this represented the most address topic shows the awareness teachers have develop and its sharing is of the most importance nor only to inspire other teachers as to develop their own practice using this reflection.

\footnotetext{
"Improving presentation skills in the context of software project management teaching" discusses an important engineering professional demand - oral communication - that not always gets the attention it deserves in the academic curricula. The authors describe the students' progress in terms of their presentation skills. Through the development of a group project, students are obliged to make several oral presentations and their presentation skills are monitored. Students get feedback from their presentations which they can use to improve themselves.
}

"Motivating Engineering students to Improve Teamwork and Time Management" debates about two essential engineering transversal competences. The authors understand its importance in order of the effect produced in terms of students' employability. Even though of its most importance, these issues are seldom taught by expecting students to have developed these skills before or by assuming they will figure it out on their own. This work implements some tools to enable students to become more efficient in their group performance.

"The application of new teaching methodologies: experience in actual situations". This work represents an effort of developing students' skills within a professional context through two academic years. The described implementation involved different methodologies in teaching and assessing. Students perception was collected. Their results show improvement of students' skills, strongly affected by their engagement.

"Practical Work and Assessment to Stimulate Student Participation and Motivation in Fluid Transport Issues" is related with the evaluation of the impact new assessment methodologies can produce on students' grades and perception. Students prefer traditional methods of assessment provided in parts along the semester. Even so, the majority are able to identify the practical work beneficial not only for their knowledge development but also for their social competences development.

\subsection{First contacts with engineering profession}

"Experience in the implementation of projects in professional environment in a 1st cycle of studies of Civil Engineering" offers the analysis of an ongoing experience of providing students with the opportunity of developing projects inside some companies. The partnership with these companies makes it possible for students to work outside academic environment. The perception of students, teachers and company advisors was surveyed and shows the success of the initiative, but also points some factors needed of adjustment in order bring closer together companies' expectations and student academic curricula.

\subsection{PBL engineering experiences and Project work in engineering education}

These two contributions brought us different levels of implementation of PBL implementations in engineering.

"Training engineering students for the world of work: a case study" addresses the gap between the abilities of the newly graduated engineers and the claimed abilities in the professional world. Presenting an innovative teaching methodology based on contextualizing theoretical concepts through real engineering problems and projects. Consequently, a better understanding of the usual abstract math and physics purpose. Results show positive outcomes related to student motivation by an improved assessment of an engineer's role. 
"Outdoor Intelligent Shader -- An EPS@ISEP 2018 Project" describes an interesting project, developed by ERASMUS students through the program European Project Semester at ISEP. Students from different nationalities and backgrounds have to work together in order to overcome scientific and technical difficulties. Through this meaningful experience students were able to develop different types of competences and relate to professional challenges, as attested by students recorded testimony.

\section{FINAL REMARKS}

Engineering Education has been addressing specific issues related to the necessary competences the labor market seeks in a professional engineer. All presented works contributed to the enhancement of the present discussion about how students are being prepared to face their professional challenges. Addressing emergent technologies, professional, scientific and social competences or projects that allow students to have their first contacts with the real world, these works represent a small but meaningful step for reflection not only for their authors but also for the reader.

\section{ACKNOWLEDGMENTS}

The chairs of this track session would like to thank the members of its Scientific Committee and all contributing authors for their efforts in enhancing the discussion upon this thematic.

The authors would also like to acknowledge the financial support provided by the Foundation for Science and Technology Project, FCT UID/EQU/04730/2013.

\section{REFERENCES}

[1] R. Wood, A. McGlashan, C-B Moon and W. Kim. 2018. Engineering Education in an Integrated Setting. iJEP, 8(3). 17-27. https://doi.org/10.3991/ijep.v8i3.7857

[2] E. Crawley, J. Malmqvist, S. Ostlund and D. Brodeur. 2007. Rethinking Engineering Education - The CDIO Approach. Springer, NY, USA.

[3] B. Johansen, Leaders Make the Future, B. Publishers, Ed., 2012.

[4] C. Viegas, A. Marques and G. Alves. 2017. $21^{\text {st }}$ Century Challenges in Engineering and Technological Learning. In Proceedings of the Fifth International Conference on Technological Ecosystems for Enhancing Multiculturality (TEEM 2017), Cadiz.

[5] L. Khaw and W. Tan. 2018. Establishing a Territory in the Introductions of Engineering Research Articles Using a Problem-Solution Patterns Approach. IEEE Transactions on Professional Communication, 61(2). 133-150.

[6] M. Iskander (Editor). 2007. Innovations in E-learning, Instruction Technology, Assessment and Engineering Education. Springer, NY, USA. 